\title{
ANALISIS PROSES SELEKSI TERBUKA JABATAN PIMPINAN TINGGI PRATAMA PEMERINTAH KABUPATEN PESAWARAN (Studi Kasus Penetapan JPTP Tahun 2020)
}

\author{
David Ariswandy, Bovie Kawulusan, Rafian Joni \\ Universitas Sang Bumi Ruwa Jurai \\ Davidariswandy@gmail.com, bovie@saburai.ac.id, rafianjoni@gmail.com
}

\begin{abstract}
Abstrak. Penelitian ini bertujuan untuk mengetahui proses seleksi terbuka jabatan pimpinan tinggi pratama Pemerintah Kabupaten Pesawaran dan Faktor - factor pendukung serta penghambatnya. Metode penelitian yang digunakan adalah kualitatif deskriptif. Objek penelitian dilaksanakan di Badan Kepegawaian dan Pengembangan Sumber Daya Manusia (BKPSDM) Kabupaten Pesawaran. Data yang digunakan adalah data primer yang diperoleh data secara langsung kepada responden dan data sekunder berupa dokumen dan jurnal yang relevan dengan penelitian. Teknik pengumpulan data menggunakan field Research dengan cara wawancara dan dokumentasi. Hasil yang di dapat antara lain, proses seleksi terbuka dilaksanakan dengan tahap: 1) Persiapan seleksi; 2) Pelaksanaan seleksi terbuka; 3) Monitoring dan Evaluasi Seleksi terbuka. Sedangkan factor pendorongnya antara lain 1) Ingin meningkatkan Kapasitas dan jenjang karir; 2) Ingin meningkatkan Kompetensi yang sesuai dengan latar belakang pendidikan dan pengalaman dalam pekerjaan atau jabatan; dan 3) Ingin meningkatkan Integritas dan komitmen dalam melaksanakan tugas jabatan. Dan yang terakhir, Faktor-faktor penghambatnya adalah 1) Belum Optimalnya Partisipasi Publik Kabupaten Pesawaran untuk mengetahui kandidat para calon pejabat (Eselon II-b) yang ikut dalam Pelaksanaan Seleksi Terbuka JPTP di Pemerintah Kabupaten Pesawaran; 2) Masih adanya penempatan pejabat pimpinan tinggi pratama (Eselon II-b) hasil Seleksi terbuka yang belum sesuai dengan latar belakang Pendidikan yang dimilikinya; dan 3) Masih adanya penempatan ASN hasil seleksi terbuka JPTP yang jenjang kepangkatannya berada satu tingkat dibawah pangkat minimal.
\end{abstract}

Kata kunci: Proses Seleksi, Jabatan Pimpinan Tinggi Pratama, Pemerintah Kabupaten Pesawaran

\section{ANALYSIS OF THE OPEN SELECTION PROCESS FOR HIGH POSITION PRATAMA GOVERNMENT OF PESAWARAN REGENCY (Case Study on Determination of JPTP in 2020)}

\author{
David Ariswandy, Bovie Kawulusan, Rafian Joni \\ Universitas Sang Bumi Ruwa Jurai \\ David_ariswandy@gmail.com,bovie@saburai.ac.id,rafianjoni@gmail.com
}

\begin{abstract}
. his study aims to determine the process of open selection of high-level leadership positions in the Pesawaran Regency Government and the supporting and inhibiting factors. The research method used is descriptive qualitative. The object of the research was carried out at the Agency for Personnel and Human Resources Development (BKPSDM) Pesawaran Regency. The data used are primary data obtained directly from respondents and secondary data in the form of documents and journals that are relevant to the research. Data collection techniques using the Research field by means of interviews and documentation. The results obtained include, among others, an open selection process carried out with the following stages: 1) Selection preparation; 2) Implementation of open selection; 3) Monitoring and Evaluation of open selection. While the driving factors include 1) Wanting to increase the capacity and career path;2) Want to improve Competence in accordance with educational background and experience in work or position; and 3) Want to improve Integrity and commitment in carrying out the duties of the position. And lastly, the inhibiting factors are 1) Not yet Optimal Public Participation of Pesawaran Regency to identify candidates for official candidates (Echelon II-b) who participate in the Implementation of JPTP Open Selection in Pesawaran Regency Government; 2) There is still the placement of high-ranking pratama (Echelon II-b) officials resulting from an open selection that is not in accordance with their educational background; and 3) There are still ASN placements resulting from the open selection of JPTP whose rank level is one level below the minimum rank. Keywords: Selection Process, Primary High Leadership Position, Pesawaran Regency Government
\end{abstract}




\section{PENDAHULUAN}

Dalam era reformasi yang berlangsung saat ini, pemerintah daerah dituntut untuk melakukan Pembaharuan dan perubahan mendasar terhadap sistem penyelenggaraan pemerintahan (Rahardi et al. 2020) terutama yang menyangkut aspekaspek organisasi, ketatalaksanaan dan sumber daya manusia. Reformasi birokrasi dilaksanakan dalam rangka mewujudkan Tata Kelola Pemerintahan yang baik (Good Governance) (Andhika 2017). Oleh sebab itu reformasi birokrasi harus dilakukan melalui langkah langkah strategis untuk membangun aparatur sipil negara agar lebih berdaya (Gosal, Dengan, and Newtsone 2019; Harahap 2016) guna dan berhasil guna dalam mengemban tugas umum pemerintahan, pembangunan dan kemasyarakatan.

Untuk mendorong keberhasilan penyelenggaraan pemerintahan yang baik / Good Governance, pemerintah daerah dalam hal ini kepala daerah dalam menjalankan roda pemerintahan harus didukung oleh professional, handal, tanggap, inovatif, dan fleksibel dan menjadi fasilitator yang dapat diandalkan oleh masyarakat pengguna layanan (Podungge and Aneta 2020). Pada perkembangan selanjutnya untuk mewujudkan aparatur sipil negara yang berkompeten pemerintah menerbitkan Peraturan Pemerintah Nomor 11 tahun 2017 tentang Menajemen Pegawai Negeri Sipil (Rasjid, Sampara, and Arsyad 2020) sebagai upaya pengelolaan Pegawai Negeri Sipil (PNS) untuk mendapatkan Pegawai Negeri Sipil (PNS) yang profesional, memiliki nilai dasar, etika profesi, bebas dari intervensi politik, bersih dari praktek Korupsi Kolusi dan Nepotisme (Harahap 2018; Octaleny 2017).

Manajemen Pegawai Negeri Sipil diarahkan guna menjamin penyelenggaraan tugas pemerintahan dan pembangunan yang berdaya guna dan berhasil guna (Aprianis 2019). Menejemen Pegawai Negeri Sipil (PNS) sebagai upaya untuk meningkatkan efisiensi, efektivitas dan derajat professionalism, penyelenggaraan tugas, fungsi dan kewajiban kepegawaian yang meliputi perencanaan, pengadaan, pengembangan kualitas, penempatan, promosi, penggajian, dan pemberhentian.

Peran Pemerintah Daerah dalam era reformasi birokrasi saat ini sangat besar dalam mewujudkan Tata Kelola Pemerintahan yang baik. Salah satu unsur Tata Kelola Pemerintahan yang baik adalah penataan aparatur pemerintahan (Kusuma 2013), yang meliputi penataan kelembagaan birokrasi pemerintahan, sistem dan penatan manajemen aparatur sipil negara. Melalui penataan tersebut diharapkan dapat terjadi perubahan dalam Tata Kelola Pemerintahan menuju Tata Pemerintahan yang demokratis dan baik. Penataan Aparatur Sipil Negara untuk menduduki suatu jabatan sebelum diberlakukannya Undang-Undang Nomor 5 Tahun 2014 Tentang Aparatur Sipil Negara. Pengisian jabatan eselon II pada lingkungan pemeritahan daerah dilaksanakan dengan cara pengangkatan oleh kepala daerah, tetapi setelah diberlakukan Undang-Undang Aparatur Sipil Negara (UUASN), pelaksanaan pengisian jabatan melalui sistem seleksi terbuka (Lusfiani and Priambodo 2019).

Jabatan Struktural merupakan kedudukan yang menujukkan tugas, tanggung jawab, wewenang dan hak seseorang Aparatur Sipil Negara (ASN) dalam rangka memimpin suatu satuan organisasi negara (Damayanti, Pangkey, and Kolondam 2016; Ismail 2016; Nope 2015). Pengangkatan Aparatur Sipil Negara (ASN) dalam jabatan struktural antara lain dimaksudkan untuk membina karier Aparatur Sipil Negara (ASN) dalam 
jabatan struktural dan kepangkatan sesuai dengan persyaratan yang ditetapkan dalam peraturan perundang-undangan yang berlaku. Untuk dapat diangkat dalam jabatan struktural seseorang harus berstatus sebagai Aparatur Sipil Negara (ASN) (Kaligis 2020), dan tidak berlaku bagi Calon Pegawai Negeri Sipil untuk dapat diangkat dalam jabatan struktural.

Persyaratan Aparatur Sipil Negara (ASN) untuk dapat diangkat hingga menduduki suatu jabatan struktural salah satunya adalah setiap pejabat yang diangkat dalam jabatan struktural haruslah memiliki kualifikasi dan tingkat pendidikan yang ditentukan (Perdana 2017), karena pada hakikatnya kualifikasi dan tingkat pendidikan akan mendukung pelaksanaan tugas dalam jabatannya secara profesional. Akan tetapi pada kenyataannya masih ditemui adanya penempatan jabatan seorang Aparatur Sipil Negara (ASN) yang tidak sesuai dengan kualifikasi pendidikannya (Mujiati, Agung, and Umbas 2021) dengan kebutuhan jabatan, hal ini akan berdampak menurunnya tingkat etos kerja pejabat yang bersangkutan yang pada akhirnya tugas pokok dan fungsi pekerjaan yang menjadi tanggung jawab bersama antara pegawai yang ada dengan pejabat yang ada dibawah koordinasinya tidak mencapai hasil yang maksimal. Untuk mendapatkan seorang pejabat yang berkualitas dan profesional, idealnya adalah melakukan seleksi terbuka dengan mempertimbangkan faktor kompetensi, integritas, kualifikasi, dan persyaratan (Handoko and Kholifah 2019) yang dimiliki oleh seorang Aparatur Sipil Negara (ASN).

Pemerintah Daerah Kabupaten Pesawaran telah beberapa kali melaksanakan seleksi terbuka Jabatan Pimpinan Tinggi Pratama untuk mengisi jabatan Eselon II-b yang lowong. Pelaksanaan seleksi terbuka Jabatan Pimpinan Tinggi Pratama (JPTP) tersebut dilakukan dengan maksud untuk memberi kesempatan kepada Aparatur Sipil Negara dilingkungan Pemerintah Daerah Kabupaten Pesawaran yang telah memenuhi persyaratan untuk mengikuti uji kompetensi dalam rangka pengembangan karir (Aprianis 2020)

Pengangkatan Pegawai Negeri Sipil (PNS) dalam jabatan struktural di lingkungan Pemerintah Daerah dilaksanakan secara berjenjang berdasarkan sistem karir dan sistem prestasi kerja (Rokhmawati 2013). Lowongan jabatan pada suatu unit organisasi diutamakan diisi oleh pegawai yang memenuhi persyaratan pada unit organisasi yang bersangkutan. Pegawai Negeri Sipil (PNS) yang akan dipromosikan dalam suatu jabatan yang lebih tinggi, diprioritaskan bagi yang sekurang-kurangnya yang setingkat dengan jabatan yang terakhir yang didudukinya.

Pada Tahun 2020 ini Pemerintah Daerah Kabupaten Pesawaran telah melaksanakan seleksi terbuka Jabatan Pimpinan Tinggi Pratama (JPTP) Eselon IIb untuk mengisi 6 jabatan yang lowong, yaitu 1) Kepala Badan Perencanaan Pembangunan Daerah; 2) Kepala Dinas Ketahanan Pangan; 3) Kepala Dinas Komunikasi dan Informatika; 4) Kepala Dinas Pemuda dan Olah Raga; 5) Staf Ahli Bidang Pemerintahan, Hukum dan Politik; dam 6) Kepala Dinas Penanaman Modal dan Pelayanan Terpadu Satu Pintu.

Pada hakikatnya kualifikasi tingkat pendidikan, jenjang kepangkatan peserta seleksi terbuka sangat berpengaruh dalam mendukung pelaksanaan tugas-tugas kedinasan (Widodo 2015) secara profesional. Pengangkatan dan penempatan jabatan hendaknya memperhatiakan jenjang pengangkatan, pada kenyatannya masih terdapat penempatan dan pengangkatan Aparatur Sipil Negara (ASN) pada Jabatan Pimpinan Tinggi Pratama (JPTP) belum sepenuhnya memperhatikan jenjang kepangkatan juga dipengaruhi oleh Peran partisipasi publik sangat minim 
untuk mengetahui para calon peserta seleksi pejabat pimpinan tinggi pratama yang mengikuti seleksi.

Penelitian sejenis sudah pernah dilakukan, antara lain penelitian yang dilakukan oleh Nasir yang menganalisis Implementasi Kebijakan Seleksi Terbuka Dalam Pengisian JPTP Di Lingkup Pemkab Toraja Utara (Nasir 2019); Penelitian oleh Aminudin, et. al yang menganalisis unsur akuntabilitas procedural seleksi terbuka JPTP Sekda kabupaten Blora (Aminudin, Sumartono, and Domai 2016); dan yang terakhir penelitian oleh handoko \& Kholifah mengenai Seleksi Terbuka JPTP BPKSDM Kabpuaten Jember (Handoko and Kholifah 2019). Keterbaruan yang diusung pada penelitian ini adalah terletak pada subjek penelitian yaitu BPKSDM Kabupaten Pesawaran serta sekaligus melihat Faktor Pendorong dan penghambatnya. Berdasarkan uraian di atas, penelitian ini bertujuan untuk mengetahui proses seleksi terbuka jabatan pimpinan tinggi pratama Pemerintah Kabupaten Pesawaran dan Faktor - factor pendukung serta penghambatnya.

\section{TINJAUAN TEORITIS}

\section{Manajemen Sumber Daya Manusia}

Manajemen sumber daya manusia merupakan salah satu bidang dari manajemen umum yang meliputi segi-segi perencanaan, pengorganisasian, pelaksanaan dan pengendalian (Almasri 2017). sumberdaya tersebut dimanfaatkan seoptimal mungkin untuk mencapai tujuan dengan upaya yang terbaik yang diberikan oleh sumber daya manusia tersebut. Dalam suatu organisasi, manusia merupakan salah satu aset organisasi yang menjadi tulang punggung suatu organisasi dalam menjalankan aktivitasnya dan pengaruhnya terhadap kinerja dan kemajuan organisasi (Muhardono and Isnanto 2014). Hal ini tentu saja harus di kondisikan agar tujuan yang berbeda dari setiap individu dalam suatu organisasi dapat disatukan sesuai dengan tujuan organisasi demi tercapainya efektivitas dan efisiensi organisasi. Menjadi tugas manajemen sumber daya manusia untuk mempelajari dan mengembangkan berbagai jalan manusia dapat di integrasikan secara efektif ke dalam berbagai organisasi yang di perlukan masyarakat.

Manajemen sumber daya manusia mempunyai tiga fungsi yaitu fungsi manajerial, fungsi operasional, dan berfungsi mencapai tujuan organisasi secara terpadu(Abdullah 2017). Salah satu kegiatan yang penting dalam manajemen SDM adalah menentukan kebutuhan SDM bagi organisasi dan menyusun rencana kegiatan untuk dapat memenuhi kebutuhan tersebut (Hengki Primayana 2016).

\section{Aparatur Sipil Negara}

Robbins (2006), dalam bukunya yang berjudul "Perilaku Organisasi", menyatakan bahwa pegawai adalah "Orang pribadi yang bekerja pada pemberi kerja, baik sebagai pegawai tetap atau tidak, berdasarkan kesepakatan kerja baik tertulis maupun tidak tertulis, untuk melaksanakan suatu pekerjaan dalam jabatan atau kegiatan tertentu yang ditetapkan oleh pemberi kerja" (Asnar 2013).

Dari definisi di atas dapat diketahui bahwa pegawai merupakan modal pokok dalam suatu organisasi, baik itu organisasi pemerintah maupun organisasi swasta. Dikatakan bahwa pegawai merupakan modal pokok dalam suatu organisasi karena berhasil tidaknya suatu organisasi dalam mencapai tujuannya tergantung pada pegawai yang memimpin dalam melaksanakan tugas-tugas yang ada dalam organisasi tersebut. Pegawai yang telah 
memberikan tenaga maupun pikirannya dalam melaksanakan tugas ataupun pekerjaan, baik itu organisasi pemerintah maupun organisasi swasta akan mendapat imbalan sebagai balas jasa atas pekerjaan yang telah dikerjakan.

Adapun pengertian Pegawai Negeri Sipil Menurut Undang-Undang No. 5 Tahun 2014 Tentang Aparatur Sipil Negara adalah: Pegawai Negeri Sipil adalah unsur aparatur sipil negara, abadi negara dan abdi masyarakat yang dengan kesetiaan dan ketaatan kepada Pancasila dan UndangUndang Dasar 1945, negara dan pemerintah, menyelenggarakan tugas pemerintahan dan pembangunan. Pegawai negeri sipil adalah mereka yang telah memenuhi syarat-syarat yang ditentukan dalam peraturan perundang-undangan yang berlaku, diangkat oleh pejabat yang berwenang dan diserahi tugas dalam sesuatu jabatan negeri atau diserahi tugas negara lainnya yang ditetapkan berdasarkan sesuatu peraturan perundang-undangan dan digaji menurut perundang-undangan yang berlaku.

Jenis pegawai di indonesia dibagi menjadi beberapa golongan. Penggolongan jenis pegawai didasarkan pada tugas pokok dan fungsi masing-masing. Hal ini bertujuan untuk memperjelas tugas dan kewajiban masing-masing pegawai. Jenisjenis pegawai indonesia telah diatur dalam Undang-undang pasal 6 Undang-undang Republik indonesia No. 5 tahun 2014 tentang Aparatur Sipil Negara yang menjelaskan bahwa Pegawai ASN terdiri dari PNS dan pegawai pemerintah dengan perjanjian kerja (Paramitha, Nurhayati, and Nita 2020). Pegawai Negeri Sipil Terdiri dari Pegawai Negeri Sipil Pusat, dan Pegawai Negeri Sipil Daerah (Kamal 2015). Secara definitif, Pegawai Negeri Sipil (PNS) daerah adalah Pegawai Negeri Sipil (PNS) daerah provinsi, daerah kabupaten dan daerah kota yang gajinya dibebankan pada Anggaran Pendapatan dan
Belanja Daerah (APBD) dan bekerja pada pemerintah daerah atau dipekerjakan diluar instansi induknya yg gajinya dibebankan pada instansi yang menerima bantuan.

\section{Seleksi Terbuka}

seleksi merupakan proses pemilihan dari sekelompok pelamar atau orang-orang yang memenuhi kriteria untuk menempati posisi yang tersedia berdasarkan kondisi yang ada pada perusahaan (Etikawati and Udjang 2016). Seleksi juga merupakan proses yang terdiri dari berbagai langkah yang spesifik dari kelompok pelamar yang paling cocok dan memenuhi syarat untuk jabatan tertentu (Sunarsi 2018).

Proses seleksi sebagai sarana yang digunakan dalam memutuskan pelamar mana yang akan diterima (Musdar, Bahri, and Zaman 2017; Pottale 2016; Pratisardy and Lukito 2019). Proses dimulai ketika pelamar melamar kerja dan diakhiri dengan keputusan penerimaan. Berdasarkan pengertian itu maka kegiatan seleksi itu mempunyai arti yang sangat strategis dan penting bagi perusahaan. Apabila dilaksanakan dengan prinsip-prinsip manajemen SDM secara wajar, maka proses seleksi akan dapat menghasilkan pilihan karyawan yang dapat diharapkan kelak memberikan kontribusi yang positif dan baik (Wulandari and Feranita 2020).

tujuan seleksi adalah untuk mendapatkan tenaga kerja yang paling tepat untuk memangku sesuatu jabatan tertentu (Nurhuda, Hamid, and Riza 2014). Dalam mengarahkan pada tujuan seleksi yang demikian itu, setiap organisasi yang bersangkutan senantiasa akan berusaha dengan biaya yang serendah mungkin dengan menggunakan cara seleksi yang paling efisien tetapi efektif. Seleksi merupakan proses yang sangat penting karena berbagai macam keahlian yang dibutuhkan oleh organisasi untuk mencapai tujuannya diperoleh dari proses seleksi. 
Proses seleksi akan melibatkan proses menduga yang terbaik (best-guest) dari pelamar yang ada (Wahyuni, Hakam, and Iqbal 2015).

\section{METODE PENELITIAN}

Metode penelitian yang digunakan adalah kualitatif deskriptif. Objek penelitian dilaksanakan di Badan Kepegawaian dan Pengembangan Sumber Daya Manusia (BKPSDM) Kabupaten Pesawaran yang beralamat di jalan Waylayap, Kecamatan Gedong Tataan, Kabupaten Pesawaran, Lampung. Data yang digunakan adalah data primer yang diperoleh data secara langsung kepada responden dan data sekunder berupa dokumen dan jurnal yang relevan dengan penelitian.

Teknik pengumpulan data menggunakan field Research dengan cara wawancara dan dokumentasi. Beberapa tahapan aktivitas dalam menganalisis data kualitatif yang diterapkan dalam penelitian ini antara lain: 1) Pengumpulan data; 2) Reduksi Data; 3) Penyajian Data; dan 4) Penarikan Kesimpulan. Bagan analisis data model interaktif tersebut dapat dilihat pada gambar berikut:

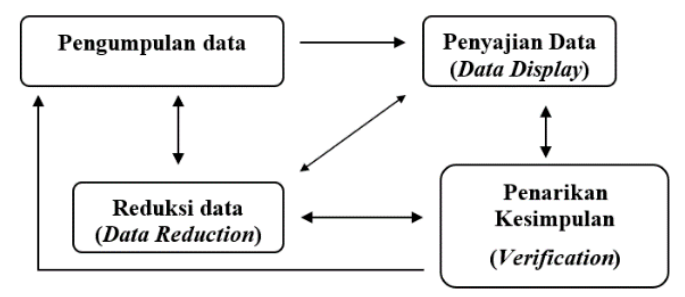

Gambar 1. Bagan Analisis Data

\section{HASIL DAN PEMBAHASAN}

\section{Proses Seleksi Terbuka Jabatan Pimpinan Tinggi Pratama Pemerintah Kabupaten Pesawaran}

\section{a. Persiapan}

Pemerintah Daerah Kabupaten Pesawaran akan melaksanakan seleksi terbuka pengisian Jabatan Pimpinan Tingi Pratama (JPTP) Eselon II-b sehubungan dengan adanya 6 jabatan Eselon II-b yang lowong, yaitu: 1) Staf Ahli Bidang Pemerintahan, Hukum, dan Politik; 2) Kepala Badan Perencanaan Pembangunan Daerah; 3) Kepala Dinas Ketahanan Pangan; 4) Kepala Dinas Komunikasi dan Informatika; 5) Kepala Dinas Pemuda dan Olahraga; dan 6) Kepala Dinas Penanaman Modal dan Pelayanan Terpadu 1 pintu.

Menurut penjelasan Kepala Badan Kepegawaian dan Pengembangan Sumber Daya Manusia (BKPSDM) Kabupaten Pesawaran Sunyoto, S.E, M.M diketahui bahwa persiapan seleksi terbuka Jabatan Pimpinan Tinggi Pratama (JPTP) tersebut dilaksanakan dengan terlebih dahulu membentuk Panitia Seleksi oleh Pejabat Pembina Kepegawaian di Instansi Daerah dengan terlebih dahulu berkoordinasi Komisi Aparatur Sipil Negara (KASN).

Dalam hal KASN belum terbentuk maka Pejabat Pembina Kepegawaian Intansi Daerah berkoordinasi dengan Menteri Dalam Negeri dan Menteri Pendayagunaan Aparatur Negara dan Reformasi Birokrasi. Sebelum dilaksanakannya proses seleksi terbuka Jabatan Pimpinan Tinggi Pratama (JPTP) Eselon II-b tersebut, maka terlebih dahulu dibentuk Panitia Seleksi yang terdiri dari unsur pejabat terkait dari lingkungan instansi yang bersangkutan, pejabat dari instansi lain yang terkait dengan bidang tugas jabatan yang lowong dan akademisi/pakar/profesional. Panitia 
Seleksi tersebut harus memenuhi persyaratan yaitu memiliki pengetahuan dan/atau pengalaman sesuai dengan jenis, bidang tugas dan kompetensi jabatan yang lowong dan memiliki pengetahuan umum mengenai penilaian kompetensi dan penyusunan serta penetapan standar kompetensi jabatan yang lowong. Panitia Seleksi berjumlah ganjil yaitu paling sedikit 5 orang dan paling banyak 9 orang. Adapun perbandingan anggota Panitia Seleksi berasal dari internal paling banyak 45\%. Panitia Seleksi melaksanakan seleksi dapat dibantu oleh Tim Penilai Kompetensi (assessor) yang independen dan memiliki pengalaman untuk membantu dalam pelaksanaan proses seleksi Jabatan Pimpinan Tinggi Pratama di lingkungan Pemerintah Daerah Kabupaten Pesawaran (Surat Pengumuman Panitia Seleksi JPTP. Kabupaten Pesawaran No. 800/01/SELTERPSW/V.04/2020).

\section{b. Pengumuman}

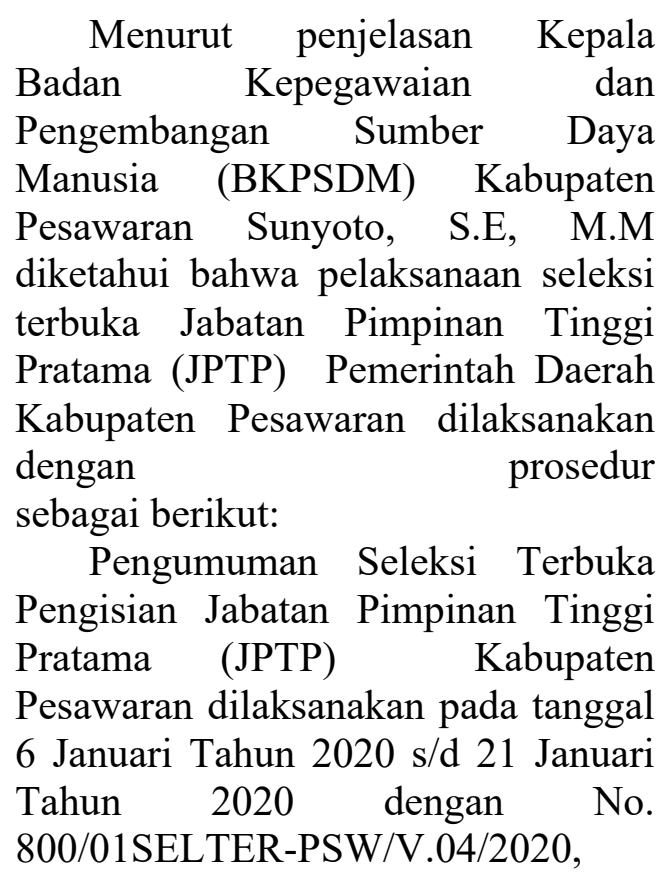

Tanggal 6 Januari 2020 yang ditandatangani oleh Ketua Panitia Seleksi pengisian Jabatan Pimpinan Tinggi Pratama secara terbuka Kabupaten Pesawaran Dr. Bovie Kawulusan, M.Si.

Untuk mengisi 6 jabatan Eselon II-b yang lowong tersebut diumumkan secara terbuka, dalam bentuk surat edaran melalui papan pengumuman, dan/atau media cetak, media elektronik (termasuk media online/internet). Pengumuman dilaksanakan paling kurang 15 (lima belas) hari kalender sebelum batas akhir tanggal penerimaan lamaran. Persyaratan Pendaftaran Seleksi Terbuka Jabatan Pimpinan Tinggi Pratama (JPTP) dengan berpedoman pada Peraturan Pemerintah Nomor 11 tahun 2017 Tentang Manajemen Pegawai Negeri Sipil.

Menurut hasil wawancara dengan Ir. Kusuma Dewangsa M.M selaku Sekretaris Daerah Kabupaten Pesawaran, diketahui bahwa pengumuman tersebut memenuhi prinsip transparansi dalam proses seleksi terbuka jabatan di lingkungan Pemerintah Kabupaten Pesawaran. Informasi yang disampaikan mencakup setiap aspek kebijakan pemerintah yang dapat dijangkau oleh publik.

Keterbukaan informasi diharapkan akan menghasilkan persaingan politik yang sehat, toleran, dan kebijakan dibuat berdasarkan pada preferensi publik. Pengumuman dalam proses seleksi terbuka jabatan pimpinan tinggi pratama di Lingkungan Pemerintah Kabupaten Pesawaran memiliki dua aspek, yaitu komunikasi publik oleh pemerintah, dan hak masyarakat terhadap akses informasi. Keduanya akan sangat sulit dilakukan jika pemerintah tidak 
menangani dengan baik kinerjanya, sehingga manajemen kinerja yang baik adalah titik awal dari transparansi. Transparansi harus seimbang juga dengan kebutuhan akan kerahasiaan lembaga maupun informasi yang mempengaruhi hak privasi individu, karena pemerintah menghasilkan data dalam jumlah besar, maka dibutuhkan petugas informasi profesional untuk menyebarluaskan keputusankeputusan yang penting kepada masyarakat serta menjelaskan alasan kebijakan tersebut. Peran media juga sangat penting bagi transparansi pemerintah, baik sebagai sebuah kesempatan untuk berkomunikasi pada publik maupun menjelaskan berbagai informasi yang relavan, juga sebagai pengawas atas berbagai aksi pemerintah dan perilaku menyimpang aparat birokrasi.

Berdasarkan penelitian dan hasil wawancara, bahwa peserta yang ikut dalam proses seleksi terbuka Jabatan Pimpinan Tinggi Pratama (JPTP) Eselon II-b sebanyak 22 orang yang terdiri dari 21 orang laki -laki dan 1 orang perempuan Aparatur Sipil Negara (ASN) yang berada di lingkungan Pemerintah Daerah Kabupaten Pesawaran. Dengan rincian identitas peserta seleksi berdasarkan usia yaitu sebagai berikut:

Tabel 1

Identitas Peserta Seleksi Terbuka JPTP Berdasarkan Usia

\begin{tabular}{cccc}
\hline No. & Umur & Jumlah & $\begin{array}{c}\text { Frekuensi } \\
(\%)\end{array}$ \\
\hline 1. & $40-45$ Tahun & 5 & 22,7 \\
2. & $46-50$ Tahun & 14 & 63,6 \\
3. & $51-54$ Tahun & 3 & 13,6 \\
\hline
\end{tabular}

\begin{tabular}{|c|c|}
\hline Jumlah & 100 \\
\hline Sumber: & Kepegawaian \\
\hline $\begin{array}{l}\text { Pengembangan Si } \\
\text { (BKPSDM) Kabupa }\end{array}$ & $\begin{array}{l}\text { ber Daya Manusia } \\
\text { Pesawaran, } 2020\end{array}$ \\
\hline
\end{tabular}

Berdasarkan tabel di atas maka dapat dilihat dari tingkat usia, diperoleh informasi bahwa peserta seleksi terbuka Jabatan Pimpinan Tinggi Pratama (JPTP) dikelompokkan menjadi tiga (3) bagian tingkat usia, peserta seleksi terbuka Jabatan Pimpinan Tinggi Pratama (JPTP) terbanyak berusia 46-50 Tahun yaitu sebanyak 14 orang (63.6\%), 46-50 Tahun sebanyak 5 orang (22.7\%), 40-45 Tahun sebanyak 3 orang (13.6\%), 51-54 Tahun.

Peserta seleksi terbuka Jabatan Pimpinan Tinggi Pratama (JPTP) berdasarkan tingkat Pendidikan yaitu sebagai berikut :

Tabel 2

Identitas Peserta Seleksi Terbuka JPTP Berdasarkan Jenjang Pendidikan

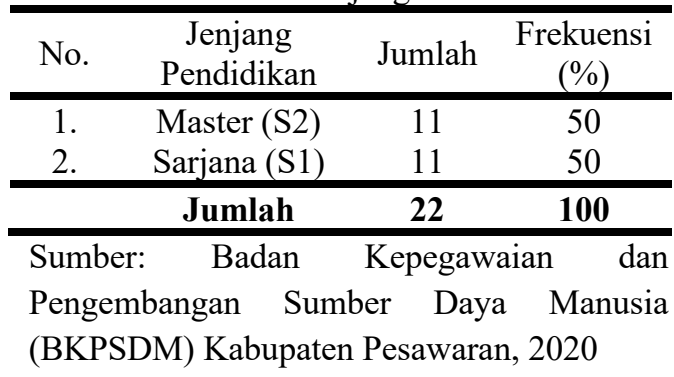

Berdasarkan Tabel diatas dapat dilihat bahwa responden yang memiliki tingkat pendidikan sarjana sebanyak 11 orang $(50.0 \%)$ dan pendidikan master (S2) sebanyak 11 orang $(50 \%)$, Jadi proporsi pendidikan antara tingkat pendidikan sarjana dan magister peserta seleksi terbuka Jabatan Pimpinan Tinggi Pratama (JPTP) yang mengikuti seleksi terbuka memiliki proporsi yang sama. 
Berdasarkan data dan hasil wawancara penulis baik terhadap panitia seleksi maupun peserta dapat dianalisis bahwa pelaksanaan proses seleksi terbuka Jabatan Pimpinan Tinggi Pratama (JPTP) kabupaten pesawaran telah berpedoman kepada Undang - Undang No 5 Tahun 2014 tentang Aparatur Sipil Negara, Peraturan Pemerintah Nomor 11 Tahun 2017 tentang Manajemen Pegawai Negeri Sipil dan Peraturan Menteri Pendayagunaan Aparatur Negara dan Reformasi Birokrasi Republik Indonesia No 13 Tahun 2014 Tentang Tata Cara Pengisian Jabatan Pimpinan Tinggi Pratama Secara Terbuka Dilingkungan Instansi Pemeritah. Adapun tahapan jadwal pendaftaran dan sampai dengan seleksi terbuka JPTP Kabupaten Pesawaran diperoleh data sebagai berikut :

Tabel 3

Jadwal Pendaftaran Dan Sampai Dengan Seleksi Terbuka Jabatan Pimpinan Tinggi Pratama (JPTP)

\begin{tabular}{|c|c|c|}
\hline No. & Kegiatan & $\begin{array}{c}\text { Waktu } \\
\text { (Tanggal) }\end{array}$ \\
\hline 1. & $\begin{array}{l}\text { Rapat Panitia/ } \\
\text { Persiapan Seleksi } \\
\text { Terbuka }\end{array}$ & 6 Jan 2020 \\
\hline 2. & Pengumuman Seleksi & $\begin{array}{c}7-21 \text { Jan } \\
2020\end{array}$ \\
\hline 3. & $\begin{array}{l}\text { Pendaftaran/ } \\
\text { Penerimaan Berkas }\end{array}$ & $\begin{array}{l}7-21 \\
2020\end{array}$ \\
\hline 4. & $\begin{array}{l}\text { Seleksi Administrasi/ } \\
\text { Penilitian Berkas }\end{array}$ & $\begin{array}{l}21 \mathrm{Jan} \\
2020\end{array}$ \\
\hline 5. & $\begin{array}{l}\text { Penetapan dan } \\
\text { Pengumuman Hasil } \\
\text { Seleksi Administrasi }\end{array}$ & $\begin{array}{c}22 \mathrm{Jan} \\
2020\end{array}$ \\
\hline 6. & $\begin{array}{l}\text { Penjelasan Tahapan } \\
\text { Pelaksanaan kepada } \\
\text { Peserta }\end{array}$ & $\begin{array}{c}23 \mathrm{Jan} \\
2020\end{array}$ \\
\hline 7. & $\begin{array}{l}\text { Pelaksaan Uji } \\
\text { Kompetensi }\end{array}$ & $\begin{array}{c}24-25 \text { Jan } \\
2020\end{array}$ \\
\hline 8. & $\begin{array}{l}\text { Penetapan dan } \\
\text { Pengumuman hasil } \\
\text { Pelaksanaan Uji } \\
\text { Kompetensi }\end{array}$ & $\begin{array}{c}25 \mathrm{Jan} \\
2020\end{array}$ \\
\hline
\end{tabular}

\begin{tabular}{|c|c|c|}
\hline 9. & $\begin{array}{l}\text { Paparan Makalah dan } \\
\text { Wawancara }\end{array}$ & $\begin{array}{c}27-28 \text { Jan } \\
2020\end{array}$ \\
\hline & Penetapan Hasil & 28 Jan \\
\hline 10. & Seleksi & 2020 \\
\hline 11. & $\begin{array}{l}\text { Penyampaian laporan } \\
\text { hasil seleksi ke PPK } \\
\text { dan Pengumuman } \\
\text { hasil Seleksi }\end{array}$ & $\begin{array}{l}29 \mathrm{Jan} \\
2020\end{array}$ \\
\hline 12. & $\begin{array}{l}\text { Penyampaian Laporan } \\
\text { Hasil Seleksi Terbuka } \\
\text { ke KASN }\end{array}$ & $\begin{array}{l}30 \mathrm{Jan} \\
2020\end{array}$ \\
\hline 13. & $\begin{array}{l}\text { Penyampaian Izin } \\
\text { Pelantikan ke } \\
\text { Gubernur dan Menteri } \\
\text { Dalam Negeri RI }\end{array}$ & $\begin{array}{c}31 \text { Jan }-10 \\
\text { Feb } 2020\end{array}$ \\
\hline
\end{tabular}

Sumber: (Surat Pengumuman Panitia Seleksi JPTP. Kabupaten Pesawaran No. 800/01/SELTER-PSW/V.04/2020)

Pelaksanaan seleksi terbuka JPTP di lingkungan Pemerintah Kabupaten Pesawaran sesuai dengan data yang diperoleh tersebut telah memberikan akses dan Informasi bahwa pelaksanaan seleksi terbuka JPTP benar-benar dilaksanakan sesuai dengan Peraturan dan Perundangundangan dan memberikan keterbukaan bagi Publik untuk mengetahui siapa-siapa kandidat pejabat yang akan dipromosikan untuk menduduki jabatan Pimpinan Tinggi Pratama Eselon II-b.

\section{c. Seleksi Administrasi}

\section{Menurut penjelasan Kepala Badan Kepegawaian dan Pengembangan Sumber Daya Manusia (BKPSDM) Kabupaten Pesawaran Sunyoto, S.E, M.M diketahui bahwa proses seleksi administrasi dalam seleksi terbuka dilaksanakan dengan tahapan sebagai berikut:}

1) Penilaian terhadap kelengkapan berkas administrasi yang mendukung persyaratan 
dilakukan oleh sekretariat Panitia Seleksi.

2) Penetapan minimal 3 (tiga) calon pejabat pejabat pimpinan tinggi pratama yang memenuhi persyaratan administrasi untuk mengikuti seleksi berikutnya untuk setiap 1 (satu) lowongan jabatan.

3) Kriteria persyaratan administrasi didasarkan atas peraturan perundang-undangan dan peraturan internal instansi yang ditetapkan oleh Pejabat Pembina Kepegawaian masing-masing.

4) Syarat yang harus dipenuhi adalah adanya keterkaitan objektif antara kompetensi, kualifikasi, kepangkatan, pendidikan dan latihan, rekam jejak jabatan, dan integritas serta persyaratan lain yang dibutuhkan oleh jabatan yang akan diduduki.

5) Dapat dilakukan secara online bagi pengumuman pelamaran yang dilakukan secara online.

6) Pengumuman hasil seleksi ditandatangani oleh Ketua Panitia Seleksi.

Tahapan seleksi/penilaian kompetensi manejerial dan kompetensi bidang (substansi tugas) Penilaian kompetensi manejerial dilakukan dengan menggunakan metodologi psikometri, wawancara kompetensi dan analisa kasus dan presentasi. Sedangkan penilaian kompetensi bidang dilakukan dengan metode tertulis dan wawancara (Standar Kompetensi Bidang disusun dan ditetapkan oleh masing-masing instansi sesuai kebutuhan jabatan dan dapat dibantu oleh assessor.

\section{d. Seleksi Kompetensi}

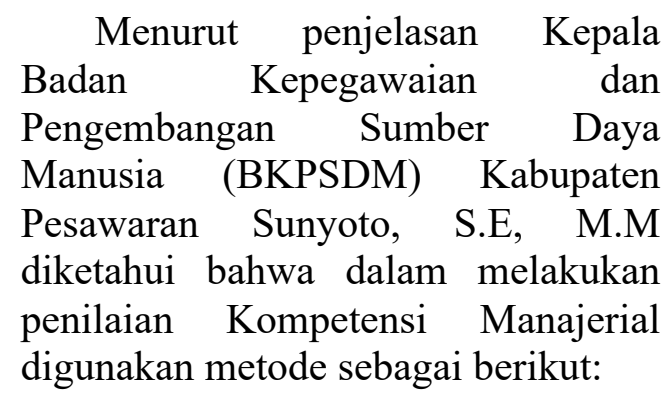

1) Untuk jabatan utama, madya dan pratama, menggunakan metode assessment center sesuai kebutuhan masing-masing instansi.

2) Untuk daerah yang belum dapat menggunakan metode assessmen center secara lengkap dapat menggunakan metode psikometri, wawancara kompetensi, analisa kasus atau presentasi.

3) Standar kompetensi manajerial disusun dan ditetapkan oleh masing-masing instansi sesuai kebutuhan jabatan dan dapat dibantu oleh assessor

4) Kisi-kisi wawancara disiapkan oleh panitia seleksi.

Dalam melakukan penilaian Kompetensi dengan menggunakan metode tertulis dan wawancara serta metode lainnya. Standar Kompetensi disusun dan ditetapkan oleh masingmasing instansi sesuai kebutuhan jabatan dan dapat dibantu oleh assessor. Standar Kompetensi Manajerial dan Kompetensi ditetapkan oleh masing-masing instansi mengacu pada ketentuan yang ada atau apabila belum terpenuhi dapat ditetapkan sesuai kebutuhan jabatan di instansi masingmasing. Hasil penilaian beserta peringkatnya disampaikan oleh Tim Penilai Kompetensi kepada Panitia Seleksi. 


\section{e. Wawancara}

Menurut keterangan Ir. Kusuma Dewangsa, M.M selaku Sekretaris Daerah Kabupaten Pesawaran diketahui bahwa wawancara akhir dilakukan oleh Panitia Seleksi dengan materi wawancara yang terstandar sesuai jabatan yang dilamar. Wawancara bersifat klarifikasi/pendalaman terhadap pelamar yang mencakup peminatan, motivasi, perilaku, dan karakter. Dalam pelaksanaan wawancara Penelusuran (Rekam Jejak) Calon dilakukan melalui rekam jejak jabatan dan pengalaman untuk melihat kesesuaian dengan jabatan yang dilamar. Selanjutnya dilakukan penyusunan instrumen/kriteria penilaian integritas sebagai bahan penilaian utama dengan pembobotan untuk mengukur integritasnya. Apabila terdapat indikasi yang mencurigakan dilakukan klarifikasi dengan instansi terkait. Panitia kemudian melakukan penelusuran rekam jejak ke tempat asal kerja termasuk kepada atasan, rekan sejawat, dan bawahan dan lingkungan terkait lainnya. Tahap selanjutnya adalah menetapkan pejabat yang akan melakukan penelusuran rekam jejak secara tertutup, obyektif dan memiliki kemampuan dan pengetahuan teknis serta melakukan uji publik bagi jabatan yang dipandang strategis jika diperlukan.

\section{f. Penetapan Hasil Seleksi}

Menurut keterangan Ir. Kusuma Dewangsa, M.M selaku Sekretaris Daerah Kabupaten Pesawaran diketahui bahwa panitia seleksi mengolah hasil dari setiap tahapan seleksi dan menyusun peringkat nilai dan mengumumkan hasil dari setiap tahap kepada peserta seleksi. Selanjutnya panitia Seleksi menyampaikan peringkat nilai kepada Pejabat Pembina Kepegawaian yang bersifat rahasia. Panitia Seleksi menyampaikan hasil penilaian jabatan pimpinan tinggi pratama (Eselon II-b) dan memilih sebanyak 3 (tiga) calon sesuai urutan nilai tertinggi. Kemudian dilakukan penetapan calon seusai dengan jabatan yang dipilih.

Dari hasil wawancara akhir dan pemaparan makalah peserta seleksi terbuka JPTP tersebut kemudian disampaikan oleh Ketua Panitia Seleksi kepada Pejabat Pembina Kepegawaian (Bupati) selanjutnya hasil tersebut disampaikan kepada Komisi Aparatur Sipil Negara (KASN) dan tembusannya disampaikan kepada Menteri Dalam Negeri, dan Menteri Pendayagunaan Aparatur Negara dan Reformasi Birokrasi. Selanjutnya hasil akhir penyampaian nama-nama peserta seleksi terbuka JPTP Kabupaten Pesawaran diperoleh rekomendasi dari Komisi Aparatur Sipil Negara tentang persetujuan nama-nama untuk menempati 6 Jabatan Pimpinan Tinggi Pratama Eselon II-b.

\section{g. Monitoring dan Evaluasi Seleksi Terbuka}

Menurut keterangan Ir. Kusuma Dewangsa, M.M selaku Sekretaris Daerah Kabupaten Pesawaran diketahui bahwa hasil seleksi terbuka Jabatan Pimpinan Tinggi Pratama (JPTP) tersebut kemudian disampaikan oleh Pejabat Pembina Kepegawaian (Bupati) kepada Komisi Aparatur Sipil Negara (KASN) dan tembusannya disampaikan kepada 
Menteri Dalam Negeri, dan Menteri Pendayagunaan Aparatur Negara dan Reformasi Birokrasi (Surat Pengumuman Panitia Seleksi Jabatan Pimpinan Tinggi Pratama (JPTP). Kabupaten Pesawaran No. 800/01/SELTER-PSW/V.04/2020).

\section{Faktor-Faktor Pendorong Proses Seleksi Terbuka Jabatan Pimpinan Tinggi Pratama (JPTP) Kabupaten Pesawaran}

Berdasarkan hasil wawancara dan penyampaian kuisioner terhadap 22 Aparatur Sipil negara (ASN) peserta seleksi terbuka Jabatan Pimpinan Tinggi Pratama (JPTP) Kabupaten Pesawaran, mayoritas diperoleh informasi sebagai berikut:

a. Ingin meningkatkan Kapasitas dan jenjang karir, yaitu dengan maksud untuk mengukur kemampuan dan pengetahuan.

b. Ingin meningkatkan Kompetensi yang sesuai dengan latar belakang pendidikan dan pengalaman dalam pekerjaan atau jabatan.

c. Ingin meningkatkan Integritas dan komitmen dalam melaksanakan tugas jabatan.

Dengan adanya seleksi secara terbuka Jabatan Pimpinan Tinggi Pratama (JPTP) Eselon II-b pada pemerintah daerah saat ini dapat memperbaiki kekurangan pada pengangkatan pejabat struktural sebelumnya yang dilaksanakan oleh Tim Baperjakat yang mempunyai tugas pokok memberikan pertimbangan dalam pengangkatan pejabat, relatif kurang berfungsi dengan baik, dikarenakan selama ini pengangkatan jabatan struktural, Sekretaris Baperjakat belum sepenuhnya menempuh mekanisme sesuai dengan ketentuan yang berlaku. Dikarenakan selama ini pengangkatan jabatan pimpinan tinggi pratama (Eselon II.b) prosedur pengangkatannya cenderung bersifat Top
Down atau langsung diarahkan atau ditunjuk oleh Kepala daerah Sehingga peran dan fungsi Baperjakat tinggal menyesuaikan saja untuk proses lebih lanjut.

\section{Faktor-Faktor Penghambat Proses Seleksi Terbuka Jabatan Pimpinan Tinggi Pratama (JPTP) Kabupaten Pesawaran}

a. Belum Optimalnya Partisipasi Publik Kabupaten Pesawaran untuk mengetahui kandidat para calon pejabat (Eselon II-b) yang ikut dalam Pelaksanaan Seleksi Terbuka Jabatan Pimpinan Tinggi Pratama (JPTP) di Pemerintah Kabupaten Pesawaran.

b. Masih adanya penempatan pejabat pimpinan tinggi pratama (Eselon II-b) hasil Seleksi terbuka yang belum sesuai dengan latar belakang Pendidikan yang dimilikinya.

c. Masih adanya penempatan Aparatur Sipil Negara (ASN) hasil seleksi terbuka Jabatan Pimpinan Tinggi Pratama (JPTP) yang jenjang kepangkatannya berada satu tingkat dibawah pangkat minimal.

Berdasarkan uraian di atas maka dapat dianalisis bahwa faktor dominan yang menjadi penghambat proses seleksi terbuka Jabatan Pimpinan Tinggi Pratama (JPTP) Pemerintah Daerah Kabupaten Pesawaran adalah masih belum optimalnya partisipasi publik dalam pelaksanaan seleksi terbuka sehingga publik tidak mengetahui siapasiapa kandidat pejabat yang mengikuti seleksi terbuka, masih adanya penempatan pejabat pimpinan tinggi pratama (Eselon IIb) Hasil Seleksi terbuka yang tidak sesuai dengan latar belakang Pendidikan yang dimilikinya, masih adanya pengangkatan 
Aparatur Sipil Negara (ASN) hasil seleksi terbuka Jabatan Pimpinan Tinggi Pratama (JPTP) yang jenjang kepangkatannya berada satu tingkat dibawah pangkat minimal.

\section{PENUTUP}

Pelaksanaan seleksi terbuka jabatan pimpinan tinggi pratama di lingkungan Pemerintah Kabupaten Pesawaran telah sesuai dengan Peraturan Pemerintah No.11 Tahun 2017 tentang Manajemen PNS, Undang-Undang No.5 Tahun 2014 tentang Aparatur Sipil Negara dan Peraturan Menteri Pendayagunaan Aparatur Negara dan Reformasi Birokrasi Republik Indonesia Nomor 13 Tahun 2014 tentang Tata Cara Pengisian Jabatan Pimpinan Tinggi Secara Terbuka di Lingkungan Instansi Pemerintah, yaitu: 1) Persiapan seleksi terbuka jabatan Pimpinan Tinggi Pratama terlebih dahulu dengan membentuk Panitia Seleksi oleh Pejabat Pembina Kepegawaian; 2) Pelaksanaan seleksi terbuka dengan prosedur sebagai berikut Pengumuman Lowongan Jabatan, Seleksi Administrasi, Seleksi Kompetensi, Wawancara Akhir, Penelusuran (Rekam Jejak) Calon, Hasil Seleksi, Tes Kesehatan dan psikologi; 3) Monitoring dan Evaluasi Seleksi terbuka.

Faktor-faktor pendorong mengikuti Seleksi Terbuka Jabatan Pimpinan Tinggi Pratama Pemerintah Kabupaten Pesawaran, antara lain: 1) Ingin meningkatkan Kapasitas dan jenjang karir, yaitu dengan maksud untuk mengukur kemampuan dan pengetahuan; 2) Ingin meningkatkan Kompetensi yang sesuai dengan latar belakang pendidikan dan pengalaman dalam pekerjaan atau jabatan; dan 3) Ingin meningkatkan Integritas dan komitmen dalam melaksanakan tugas jabatan.

Faktor-faktor penghambat Pelaksanaan seleksi terbuka pejabat pimpinan tinggi pratama di lingkungan
Pemerintah Kabupaten Pesawaran adalah 1) Belum Optimalnya Partisipasi Publik Kabupaten Pesawaran untuk mengetahui kandidat para calon pejabat (Eselon II-b) yang ikut dalam Pelaksanaan Seleksi Terbuka JPTP di Pemerintah Kabupaten Pesawaran; 2) Masih adanya penempatan pejabat pimpinan tinggi pratama (Eselon IIb) hasil Seleksi terbuka yang belum sesuai dengan latar belakang Pendidikan yang dimilikinya; dan 3) Masih adanya penempatan ASN hasil seleksi terbuka JPTP yang jenjang kepangkatannya berada satu tingkat dibawah pangkat minimal.

Dari analisis di atas, peneliti memiliki saran antara lain : 1) Pelaksanaan seleksi terbuka JPTP Kabupaten Pesawaran agar lebih konsisten sesuai dengan kompetensi, prestasi kerja dan jenjang kepangkatan yang ditetapkan untuk penempatan ASN dalam suatu jabatan khususnya jabatan pimpinan tinggi pratama; dan 2) Faktor-faktor penghambat yang ada hendaknya diminimalisir sehingga dapat diperoleh pejabat yang professional, berkompeten dibidangnya guna menunjang tugas pokok dan fungsi pekerjaannya dalam membantu pimpinan (Kepala Daerah) terhadap tugas tugas pemerintahan, pembangunan, dan kemasyarakatan.

\section{DAFTAR PUSTAKA}

Abdullah, Husaini. 2017. "Peranan Manajemen Sumberdaya Manusia Dalam Organisasi." Jurnal Warta Dharmawangsa 51.

Almasri, M. Nazar. 2017. "Manajemen Sumber Daya Manusia: Imlementasi Dalam Pendidikan Islam." Kutubkhanah: Jurnal Penelitian Sosial Keagamaan 19(2):133-51. doi: 10.1002/eji.201370106.

Aminudin, M., Sumartono, and Tjahjanulin Domai. 2016. "Akuntabilitas Seleksi 
Terbuka Jabatan Pimpinan Tinggi

Pratama Sekretaris Daerah

Kabupaten Blora." JPSI (Journal of

Public Sector Innovations) 1(1):1-6.

Andhika, Lesmana Rian. 2017. "Evolusi

Konsep Tata Kelola Pemerintah:

Sound Governance, Dynamic

Governance Dan Open

Government." Jurnal Ekonomi Dan

Kebijakan Publik 8(2):87-102. doi:

10.22212/jekp.v8i2.867.

Aprianis. 2019. "PENGARUH

KOMUNIKASI INTERNAL DAN

KOMPETENSI PEDAGOGIK

TERHADAP KINERJA GURU

PADA SMPN 1 ABUNG TENGAH

KABUPATEN LAMPUNG

UTARA." Jurnal Ilmu Manajemen

Saburai (JIMS) 5(2):9-18.

Aprianis. 2020. "EVALUASI KINERJA

GURU YANG DIPENGARUHI

OLEH GAYA KEPEMIMPINAN

DAN MOTIVASI KERJA GURU

PADA SMP NEGERI 1 NEGARA

BATIN KABUPATEN WAY

KANAN.” Jurnal Ilmu Manajemen

Saburai (JIMS) 6(1):37-44.

Asnar, Zaid Habibie. 2013. "Pengaruh Tata

Ruang Kantor Terhadap Aparatur

III Lembaga Administrasi Negara

(PKP2A III LAN) Samarinda."

EJournal Ilmu Pemerintahan

1(4):1488-1500.

Damayanti, Eriska, Masye Pangkey, and

Helly Kolondam. 2016.

"Implementasi Sistem Promosi

Pejabat Struktural Di Sekretariat

Daerah Kota Bitung." Jurnal

Administrasi Publik UNSRAT 3(41).

Etikawati, Ena, and Raswan Udjang. 2016.

"Strategi Rekrutmen Dan Seleksi

Terhadap Kinerja Karyawan."
Jurnal Perilaku Dan Strategi Bisnis 4(1):9-23. doi:

10.26486/jpsb.v4i1.443.

Gosal, Ronny, Penelitian Dengan, and John W. Newtsone. 2019. "Disiplin Aparatur Sipil Negara Dalam Melaksanakan Tugas Pokok Dan Fungsi Di Kecamatan Kawangkoan Kabupaten Minahasa." Jurnal Eksekutif 3(3):1-11.

Handoko, Rizal Bagus Dwi, and Emy Kholifah. 2019. "Seleksi Terbuka Jabatan Pimpinan Tinggi Pratama (Studi Pada Badan Kepegawaian Dan Pengembangan Sumber Daya Manusia Kabupaten Jember 2019).” Prosiding Simposium Nasional 1208-41.

Harahap, Nurmalita Ayuningtyas. 2016. "Penguatan Kedudukan Dan Peran Komisi Aparatur Sipil Negara Dalam Mewujudkan Reformasi Birokrasi." Jurnal Panorama Hukum 1(2):83. doi: 10.21067/jph.v1i2.1418.

Harahap, Nurmalita Ayuningtyas. 2018. "Revitalisasi Manajemen Aparatur Sipil Negara Melalui Pemberhentian Tidak Dengan Hormat Bagi Pegawai Negeri Sipil Yang Terlibat Tindak Pidana Korupsi." Jurnal Panorama Hukum 3(2):155-70. doi: 10.21067/jph.v3i2.2737.

Hengki Primayana, Kadek. 2016. "Manajemen Sumber Daya Manusia Dalam Peningkatan Mutu Pendidikan Di Perguruan Tinggi." Jurnal Penjaminan Mutu 1(2):7-15. doi: 10.25078/jpm.v1i2.45.

Ismail, Mahli. 2016. "Kewenangan Pemerintah Terhadap Pendistribusian Dan Pemanfaatan 
Tanah Negara Dalam Islam." MIQOT: Jurnal Ilmu-Ilmu

Keislaman 37(1):27-45.

Kaligis, Rainaldy Valentino. 2020.

"Implikasi Hukum Atas Revisi

Undang-Undang Nomor 30 Tahun

2002 Tentang KPK Terhadap

Penyelesaian Kasus Tindak Pidana

Korupsi." LEX CRIMEN 9(1):140 50.

Kamal, Fahmi. 2015. "Tinjauan Pendidikan Dan Pelatihan Untuk Pegawai Negeri Sipil Pada Suatu Instansi Pemerintah." Perspektif 13(1):2030.

Kusuma, Dirk Malaga. 2013. "Kinerja Pegawai Negeri Sipil (PNS) Di Kantor Badan Kepegawaian Daerah Kabupaten Kutai Timur.” Jurnal Administrasi Negara 1(3):13881400.

Lusfiani, Andi Yuni, and Rinto Priambodo. 2019. "Analisis Dan Perancangan Aplikasi Jabatan Pimpinan Tinggi Pratama (SIJAPTI) Kantor Komisi Aparatur Sipil Negara." Jurnal Sisfokom (Sistem Informasi Dan Komputer) 8(2):199. doi: 10.32736/sisfokom.v8i2.626.

Muhardono, Ari, and Rizal Isnanto. 2014. "Penerapan Metode AHP Dan Fuzzy Topsis Untuk Sistem Pendukung Keputusan Promosi Jabatan.” Jurnal Sistem Informasi Bisnis 4(2):108-15. doi: 10.21456/vol4iss2pp108-115.

Mujiati, Fatmawati, Sugiantiningsih Agung, and Ronald Umbas. 2021. "Pengaruh Kualifikasi Pendidikan Terhadap Penempatan Kerja Aparatur Sipil Negara (ASN)." Jurnal Ilmu Sosial Dan Ilmu Politik
35(1):25-36. doi:

10.52318/jisip.2021.v35.1.3.

Musdar, Izmy Alwiah, Syamsul Bahri, and Baizul Zaman. 2017. "Implementasi Metode Decision Tree Pada Sistem." Jtriste 4(1):72-81.

Nasir. 2019. "Implementasi Kebijakan Seleksi Terbuka Dalam Pengisian Jabatan Pimpinan Tinggi Pratama Di Lingkup Pemerintahan Kabupaten Toraja Utara." Kolaborasi : Jurnal Administrasi Publik 5(2):154-74.

Nope, Nelson Bastian. 2015. "Mutasi Pejabat Fungsional Ke Dalam Jabatan Struktural Di Era Otonomi Daerah." Masalah-Masalah Hukum 44(2):234. doi: 10.14710/mmh.44.2.2015.234-242.

Nurhuda, Erwin, Djamhur Hamid, and M. Faisal Riza. 2014. "Analisis Pelaksanaan Program Rekrutmen, Seleksi, Penempatan Kerja, Dan Pelatihan Karyawan (Studi Pada Karyawan Biro Perjalanan Umum Rosalia Indah)." Jurnal Administrasi Bisnis S1 Universitas Brawijaya 9(1):81170.

Octaleny, Ellyza. 2017. "Manajemen Aparatur Sipil Negara Dalam Mewujudkan Profesionalisme Dan Daya Saing Aparatur Sipil Negara." Jurnal Pemerintahan Dan Politik 2(1):1-6.

Paramitha, Nabila, Siti Nurhayati, and Surya Nita. 2020. "Status Hukum Pegawai Pemerintah Dengan Perjanjian Kerja (PPPK) Terhadap Perjanjian Kontrak Kerja Ditinjau Dari Undang-Undang Nomor 5 Tahun 2014 Tentang Aparatur Sipil 
Negara (Studi Penelitian: Dinas Sosial Kota Medan)."

Perdana, andre Pebrian. 2017. "Penerapan Prinsip-Prinsip Good Governance (Studi Kasus Dalam Proses Pengangkatan Pejabat Struktural Eselon II Di Lingkungan Pemerintah Kota Bandar Lampung)." Jurnal Kelitbang 4(01):81-90.

Podungge, Abdul Wahab, and Asna Aneta. 2020. "Profesionalisme Pegawai Ditinjau Dari Aspek Pengorganisasian Dalam Pelayanan Publik." Publik (Jurnal Ilmu Administrasi) 9(1):55. doi: 10.31314/pjia.9.1.55-65.2020.

Pottale, Billy. 2016. "Pengaruh Proses Rekrutmen Dan Seleksi Terhadap Kinerja Karyawan Pada Pt Bank Sulutgo.” Jurnal Berkala Ilmiah Efisiensi 16(4):453-64.

Pratisardy, Essy, and Hendra Lukito. 2019. "Dampak Rekrutmen, Seleksi, Dan Motivasi Terhadap Kinerja Karyawan Pt Bank Xyz Tbk Cabang Padang." Jurnal Ekonomi Dan Bisnis 21(1):14-22.

Rahardi, Fauzi Hafizh, Andi Bayu Daffa, Tandri Ajeng, and Maudi Yuningsih Partotaruno. 2020. "Spoil System Sebagai Tantangan Penyelenggaraan Pemerintahan Di Era Digitalisasi." Prosiding Simposium Nasional "Tantangan Penyelenggaraan Pemerintahan Di Era Revolusi Indusri 4.0" 13781401.

Rasjid, Ilham, Said Sampara, and Nasrullah Arsyad. 2020. "Efektivitas Peraturan Pemerintah Nomor 11 Tahun 2017 Tentang Manajemen
Pegawai Negeri Sipil Terhadap Disiplin Pegawai Di Pemerintah Kota Palopo." Journal of Lex Theory (JLT) 1(1):19-40. doi: 10.52103/j1t.v1i1.42.

Rokhmawati, Puspita. 2013. “Analisis Penilaian Prestasi Kerja Pegawai." Jurnal Dinamika Manajemen 4(1):23-29.

Sunarsi, Denok. 2018. "Pengaruh Rekrutmen, Seleksi Dan Pelatihan Terhadap Produktivitas Kerja Karyawan." Jurnal KREATIF : Pemasaran, Sumberdaya Manusia Dan Keuangan 6(1):14-31.

Wahyuni, Sri, Moehammad Soe'oed Hakam, and Mohammad Iqbal. 2015. "Analisis Mekanisme Seleksi Berbasis Pendekatan Teori Human Capital." Administrasi Bisnis 21(1):1-7.

Widodo, Wahyu. 2015. "Peran Manajemen Sumber Daya Manusia Dalam Upaya Peningkatan Motivasi Kerja Pegawai (Studi Di Kantor Satuan Polisi Pamong Praja Kabupaten Lampung Timur)." Derivatif 9(1):107-14.

Wulandari, Tri Oktavia, and Nungky VIana Feranita. 2020. "Pengaruh Proses Rekrutmen Dan Seleksi Terhadap Kinerja Karyawan Koperasi Simpan Pinjam (KSP) Mulia Jaya.” Majalah Ilmiah" CAHAYA ILMU" 2(1):4456. 